\title{
SERVIÇO SOCIAL CRÍTICO: DA MODERNIDADE À CONTEMPORANEIDADE
}

\author{
Critical social work: from modernity to contemporaneity \\ Helena Belchior Rocha ${ }^{1}$, Paula Marques Ferreira ${ }^{2}$, Teresa Paula Silva ${ }^{3}$, \\ VANDA BRAZ RAMALHO ${ }^{3}$
}

\section{Resumo}

O Século XXI e o desafio da contemporaneidade, implicam para o Serviço Social diferentes horizontes teóricos e diferentes abordagens de prática, no enfrentamento da «questão social» e na promoção de conceções de mudança social. Com o objetivo de entender o imanente e o explícito no questionamento dos fundamentos normativos e dos fundamentos que sustentam a crítica no Serviço Social, e ainda de localizar no amplo debate da Teoria Social Contemporânea as influências dos pensadores, da Teoria Social clássica, da Escola de Frankfurt e mais recentemente pelas teorias pós estruturalistas, as reflexões do presente artigo abarcam do contexto de surgimento das teorias críticas ao Serviço Social crítico contemporâneo, seus princípios e fundamentos e por fim a teoria crítica pósmoderna na sua dimensão ontológica, epistemológica e metodológica.

Palavras chave: Serviço Social, Teoria Crítica, Pós-modernismo

\begin{abstract}
The XXI Century and the challenge of contemporaneity implies for Social Work different horizons and different theoretical approaches of its practice in combating the «social issue» and promoting conceptions of social change. In order to understand the inherent and explicit in questioning the normative foundations and fundamentals that underpin critical in social work, and even to locate the broad debate of Contemporary Social Theory influences of its thinkers, Classical Social Theory, Frankfurt School and more recently the post structuralist theories, the reflections of this article cover the context of the emergence of critical theories to critical contemporary Social Work, its principles and foundations and finally postmodern critical theory in its ontological, epistemological and methodological dimensions.
\end{abstract}

Keywords: Social Work, Critical Theory,

Postmodernism

1. Centro de Investigaçao e Estudos de Sociologia (CIES).

2. Responsable de la correspondencia. Centro de Investigação e Estudos de Sociologia (CIES). Edifício ISCTE. Av. das Forças Armadas. 1649-026 Lisboa (Portugal). +351 960073849

3. Centro Lusíada de investigação em Serviço Social e Intervenção Social. Universidade Lusíada de Lisboa. Instituto Superior de Serviço Social, Lisboa, Portugal. 


\section{Introdução}

O seguinte artigo pretende reflectir sobre tendências e perspectivas da produção do conhecimento do Serviço Social num mundo globalizado - da teoria normativa à teoria crítica.

O Século XXI, sendo um século de «descentramentos» (Restrepo, 2003: 7), onde propostas de modelos se (re)estruturam e se (re)desenham, exigem do Serviço Social a necessidade de reflectir sobre o sentido histórico e epistemológico dos sistemas teóricos que os fundamentam a fim de estabelecer quebras e rupturas com discursos, conceitos, métodos e práticas que no passado foram considerados como definitivos.

Por esta ordem de razão, o imaginário e a visão do Serviço Social estão marcados por interpretações restritivas do processo de modernidade e pela assunção de modelos teóricos que dificultam a compreensão das sociedades complexas contemporâneas (Restrepo, 2003). Impõe-se ao Serviço Social contemporâneo o desafio de estabelecer categorias teóricas e metodologias que ampliem o seu horizonte interdisciplinar e estimulem a concepção do ser humano como construtor da sua própria realidade.

Em Teoria Social, a questão da «base normativa» ou dos fundamentos que sustentam a crítica tem vindo a ganhar um interesse crescente. Enquanto as teorias sociais empíricas podem deixar com maior facilidade a sua fonte normativa num estado implícito, pois visam mais a explicação do que a avaliação, o mesmo não acontece com as teorias críticas, que se posicionam como guias para a acção humana, pois sendo reflexivas, visam esclarecer e emancipar os agentes de coerções, muitas vezes, auto impostas (Geuss, 1988: 8).

Habermas, que provém da tradição crítica alemã em teoria social, tornou a questão da justificação imanente completamente explícita, adoptando um critério transcendente de racionalidade para criticar o capitalismo, passando a olhar com desconfiança para os seus fundamentos normativos (Habermas, 1987: 347-402). Para abordar estas questões parte-se neste trabalho para a abordagem de aspectos centrais da teoria crítica: contexto do seu surgimento, princípios e fundamentos, e teoria crítica pós-moderna.

\section{Enquadramento da Teoria Crítica: contexto de surgimento}

Num contexto marcado pelos movimentos sociais e pelo despontar das teorias sociais críticas, assiste-se, no início dos anos 70 do séc. XX, no Serviço Social, aquilo que se pode designar por uma reorientação crítica da teoria da prática.

Marcados pela oposição ao carácter individualista das teorias ortodoxas do Serviço Social, em especial as psicanalíticas que vigoravam desde a década 
de 20, os assistentes sociais procuraram o questionamento reflexivo das generalizações modernas e da visão conservadora dos antepassados da profissão (Adams, 1961; Parker, 1961; Reynolds, 1963; Kravetz, 1976; Franklin, 1986; Van Krieken, 1992, in Healy, 2001).

Contudo, e apesar dos múltiplos contributos que este questionamento trouxe para a profissão, ainda hoje, esta prática crítica carece, segundo Rojek (in Healy, 2001), em grande medida, de enquadramento teórico.

Esta situação deriva, segundo Howe, da subjetividade e complexidade com a qual têm de lidar as ciências sociais e humanas, às quais não escapa o Serviço Social contemporâneo. Como refere o autor, «the social and psychological sciences therefore have to deal with subjective experience as well as objective reality - what people think, fell, and believe as well as what they say and do. This is why language and the quality of the relationship are so important in the conduct of Social Work» (Howe, 2009: 4).

Assim, assistimos, segundo Payne (2002), a um debate epistemológico do Serviço Social centrado em duas visões: - a visão moderna ou positivista (Cristopher Bryant, 1985; Saint-Simon; Durkheim; Weber e Habermas] e a visão pós-moderna da teoria do Serviço Social (Foucault, 1972; Chambon e Irving, 1994; Howe, 1994; Pardeck e Parton, 1994).

Para o autor, numa visão positivista ou moderna a teoria do Serviço Social consiste «numa aplicação estrita do método científico (...) uma afirmação geral sobre o mundo real» (Payne, 2002: 59). Já nas visões pós-modernistas, Payne reconhece um significado mais amplo para o entendimento das teorias do Serviço Social, que são entendidas quer como um sistema de classificação que permite explicações sistemáticas, quer como um enquadramento ou disciplina ou ainda como teoria explanatória de uma determinada acção (Payne, 2002).

Para Healy, os antecedentes intelectuais do Serviço Social crítico contemporâneo são diversificados e recorrem a um amplo conjunto de teorias sociais críticas, que vão desde as teorias feministas, ao marxismo, ao desenvolvimento comunitário, à teoria radical da educação de Paulo Freire (1970), à antipsiquiatria, à sociologia radical, à teologia da libertação, etc., que por sua vez deram lugar a diferentes modelos que podem ser considerados críticos: serviço social anti-racista e multicultural, anti-opressor e anti-discriminativo, feminista e serviço social radical (Healy, 2001).

A teoria crítica do Serviço Social absorveu uma concepção geral das ideias da ciência social crítica acerca da natureza do mundo social e da existência humana, tentando compreender o mundo de forma a poder transformá-lo, patente no objectivo de mudança social, que trespassa, hoje, a profissão. 
Nos antecendentes da ciência social crítica contemporânea, que se encontram na base do Serviço Social crítico, encontramos, num primeiro momento, as influências de Hegel (1770-1831) e Marx (1818-1883) no que concerne à sua insistência na capacidade humana de, mediante uma acção consciente e colectiva, transformar a sociedade, fazendo vingar uma visão emancipadora, livre da dominação.

Contudo, no entender desta autora, tratam-se de influências que se revelam incapazes ou insuficientes para dar resposta aos desafios resultantes das mutações sociais da contemporaneidade.

Surgem também como relevantes os contributos pós-estruturalistas, sob a influência de Foulcault (1926-1984) e dos movimentos feministas radicais (Healy, 2001).

Adams, Dominelli e Payne (2009) identificam 3 grandes grupos comumente referidos como teorias sociais críticas:

- Marxismo: «Marxists would say that conventional Social Work practices support and extend the oppressive power of social institutions in capitalist states» (Adams, Dominelli \& Payne, 2009: 10);

- Escola de sociologia de Frankfurt: (Horkheimer (1978); Adorno (1979) e Marcuse (1964): "The Frankfurt theorists argue that we treat our cultural and ideological heritage as given, whereas these elements of society are crucial elements in how we may be dominated by a capitalist, authoritarian state.» (Ibidem).

- Sucessores da escola de Frankfurt, como Habermas (1984, 1987): «Habermas distinguishes between the system and the lifeworld, wich interact and some extent conflict with each other» (Ibidem).

Recentemente, abordagens alternativas do Serviço Social crítico apoiam-se nas teorias pós-modernas (como Fook e Gardner, 2002-2007), cujo foco é feito "on the way in which understanding of the world reflects personal experience and social and historical context» (Adams et al., 2009: 11).

Segundo estes autores, o Serviço Social crítico contemporâneo, permeado pelo contributo das teorias pós-estruturalistas, permite orientar uma prática crítica, reflexiva, com cariz de intencionalidade, participação, permitindo, ainda, a extensão da intersubjectividade na compreensão da realidade social. Com efeito, nas palavras destes, "reflective practice and critical reflection are methods of interpreting social knowledge, professional and social values and agency and policy aims into practice actions. The reflective cycle and processes of critical reflection enable practitioners to use ideas from practice theories to develop and renew their practice» (Adams et al., 2009: 91). 
Apesar de algumas reticências da profissão em integrar os contributos recentes das teorias pós-modernas, é importante, reconhecer que estes apelam à adopção de uma postura crítica reflexiva sobre os efeitos negativos de alguns ideais utópicos do Serviço Social crítico activista, que acabou por não conseguir romper com a tradição assistencial na profissão.

As correntes pós-modernas, e dentro destas as teorias pós-estruturais, desafiam o Serviço Social a centrar-se em propostas locais e contextuais, a reexaminar os seus problemas práticos relacionando-os com os problemas locais de poder, identidade e mudança, tendo em vista a qualificação da sua prática para responder aos novos problemas sociais (Healy, 2001; Fook, 2001).

\section{A Teoria Crítica: princípios e fundamentos}

Influenciada pela Teoria Social Clássica (com destaque para as obras de Marx e Hegel), pela moderna Escola Crítica de Frankfurt e, recentemente (década de 90), pelas teorias pós-estruturalistas, a teoria crítica social do século XX apresenta-se como uma nova forma de estar, de pensar e de conhecer a realidade social.

As suas repercussões ao nível do Serviço Social são notórias, conduzindo ao surgimento de um corpo diferenciado de teorias práticas críticas e que vêm pôr em causa a auto e hetero imagem ocupacional e assistencial da profissão (Rojek, 1988 e Sarri e Sarri, 1992 in Healy, 2001).

Com efeito, um ponto-chave da teoria crítica social que influenciou o Serviço Social é o seu enfoque em compreender o mundo para transformá-lo e a importância da razão e da acção humanas para a configuração da sociedade (Healy, 2001).

Segundo Howe, "critical theorists examine the socially constructed character of society. They show how ruling and powerful social groups are able to justify injustice and inequality by their control of the language, media, education, political agenda and terms of debate» (Howe, 2009: 130).

Neste ponto, a influência da dialéctica materialista de Hegel e Marx é clara. Insistindo na relação dialéctica entre pensamento e realidade, o sujeito assume-se como agente que transforma o objecto que observa. É a razão autoconsciente que capacita os humanos para reconhecer a sua relação dialéctica com o mundo (Fay, 1987 in Healy, 2001), sendo nesta relação com a totalidade social que todos os acontecimentos e a experiência se produzem (Hegel, 1910).

Neste processo de transformação, a consciencialização e a acção colectiva sobre as estruturas sociais revelam-se fundamentais, segundo Marx que 
considera que a libertação humana de uma relação de dominação requer a transformação da realidade material.

Analisando o desenvolvimento da Teoria Crítica no Séc. XX, podemos observar os enormes contributos da Escola de Frankfurt com as obras de Horkeimer (1895-1973), Adorno (1903-1969), Marcuse (1898-1979) e Habermas (1929). A escola de Frankfurt afirma que as relações de dominação se introduziram nas formas culturais modernas. Horkeimer e Adorno defendem que a razão ficou comprometida ao incorporar-se na estrutura da sociedade capitalista, advogando um pensamento que não seja puramente abstracto e que permita uma crítica emancipatória (Kellner, 1989 in Healy, 2001).

Habermas, defende ao contrário de outros autores da escola Frankfurt, a modernidade como ideal inacabado ao invés de um projeto irrealizável (Lechte, 1994 in Healy, 2001).

A sua obra, centrada numa teoria crítica e emancipatória, procura responder às questões, desafios, projectos e contradições da contemporaneidade, sendo conhecido pelo estudo persistente dos problemas da natureza da comunicação, da autoconsciência, do seu papel causal na acção social e pela sua proposta de uma teoria do agir comunicativo, como alternativa de explicação e construção da sociedade.

Habermas dedica-se, assim ao estudo da acção comunicativa, investigando as limitações da comunicação racional e promovendo a compreensão intersubjectiva. Para o autor, a transformação social parte da promoção do debate público e do consenso sobre as questões relativas às necessidades humanas.

O problema central das sociedades contemporâneas, para Habermas, não é a compreensão de como é mantida a ordem social, mas sim como criar condições para o que chama de «acção comunicativa».

Tal como Parsons, Habermas considera que as sociedades exigem a integração, mas como os neo-marxistas, advoga que as sociedades que denomina de capitalismo avançado, se encontram num profundo processo de crise, de legitimação das instituições sociais e do Estado e de motivação, no que concerne à identificação de sentido para a existência humana, reduzindo a função integradora do núcleo de comunicação. O núcleo da sua Teoria do Agir Comunicativo consiste em descrever esta crise societal como colonização do mundo da vida pelos sistemas (Habermas, 1987, 1990).

Nas palavras de Ahlert, este novo paradigma, «centrado na linguagem intersubjetiva de diferentes sujeitos, possibilita a retomada para a comunidade das questões da justiça, do dever, da verdade e da liberdade.» Com efeito, podemos verificar como Habermas propõe que, "para além do elemento 
cognitivo-instrumental a racionalidade comunicativa permite integrar também os elementos prático-moral e estético-expressivo» (Ahlert, s.d.: 5).

Verifica-se uma dupla proposta no pensamento de Habermas, quando este nos fala de uma teoria do agir comunicativo, como teoria social: o modelo do 'sistema', que se refere à 'reprodução material', regido pela lógica instrumental, de relações de poder e o modelo do 'mundo da vida', que por sua vez se refere ao campo da 'reprodução simbólica', ou seja, dos significados que compõem uma visão de mundo.

Assim, ao propor uma teoria do agir comunicativo, Habermas desejaria encontrar uma solução em prol da integração social democrática, que levasse ao exercício de uma cidadania plena e à resolução de conflitos sociais, através do consenso comunicacional e discursivo para a justiça.

Destes contributos destacam-se algumas características relevantes para o Serviço Social crítico:

- A reflexão racional que proporciona uma base vital para a acção radical. Compreensão da sociedade como totalidade (Wearing, 1986).

- A estrutura social global que ordena o sentido fundamental das relações sociais, nos níveis institucionais e individuais. As experiências locais surgem como efeitos de uma estrutura social global, na qual a posição de oprimido e opressor se encontra determinada pela estrutura social (Balibar, 1977).

- Relevam a dimensão do poder, da luta dialéctica entre grupos sociais opostos (Mullaly, 1993).

- Os humanos produzem e são produto da sociedade. Os seres humanos são configurados pela estrutura social, mas são também capazes de alterá-la.

- Promoção do pensamento racional, autoconsciente no processo de emancipação pessoal e social (Corrigan e Leonard, 1978).

- Capacitação dos sujeitos para transformar a ordem social. Insiste na capacidade dos sujeitos para transformar a sociedade (Fay, 1987).

Segundo Healy, nas correntes críticas as estratégias de conciencialização individual e coletiva são importantes como meio de compreender, reflexivamente, a organização da estrutura social, levando ao questionamento das visões do mundo naturalizadas e auto-limitadoras, interiorizadas pelos oprimidos. Com efeito, a consciencialização é fundamental e precursora da acção social radical (Healy, 2001).

Não havendo uma abordagem única, é, sobretudo, uma visão da sociedade como totalidade, uma valorização da estrutura social global, como factor 
de organização das relações sociais, a indiferenciação entre poder e dominação e a consciencialização dos 'oprimidos' para processos de emancipação e mudança estrutural, que une estas diferentes correntes teóricas.

A estas, Healy acrescenta as teorias pós-estruturalistas, onde se incluem as obras de Foucault e do feminismo radical, como referências centrais na construção da teoria crítica pós-estruturalista do Serviço Social. Estas novas perspectivas têm em vista a compreensão da importância da linguagem na explicação e produção da realidade social, da diversidade das práticas sociais e locais e dos seus efeitos, numa perspectiva indutiva de análise, que valoriza a compreensão da diversidade das identidades culturais e a aceitação das representações sociais como parcelares e provisórias (Healy, 2001).

Surgidas com mais relevância nos anos 90, as teorias pós-estruturalistas apresentam 3 orientações importantes para o Serviço Social crítico contemporâneo (Foulcault, 1981; Leonard, 1994; Scott, 1992 in Healy, 2001):

- Risco de incerteza e ambiguidade para guiar a prática; dificuldades em definir os limites teóricos da diferença;

- A prática crítica passa a estar enquadrada nos contextos históricos e locais em que se encontram imersas as práticas do Serviço Social;

- Oportunidade para transcender pressupostos racionalistas modernos na prática profissional.

Ao centrar-se nas representações da prática, a teoria pós-estruturalista dirige, sobretudo, a sua atenção para os discursos mediante os quais se produz o Serviço Social crítico, aumentando a reflexividade dos profissionais, questionando sobre a forma como se constroem as relações locais de poder, desconstruindo as oposições identitárias dualistas e reconhecendo a importância da diversidade e dos contextos específicos de acção na operacionalização da mudança social, promovendo novas concepções de mudança, focadas em aspectos mais irracionais e emocionais do saber.

Desta forma, o pós-estruturalismo afirma-se como um contributo teórico -prático que "puede contribuir al establecimiento de unas formas nuevas y más respetuosas de afrontar las diferencias» (Healy, 2001: 85).

\section{A teoria crítica pós-moderna}

Numa reviravolta pós-moderna surgem, nos últimos anos novas abordagens de cariz pós-estruturalista no seio das teorias críticas do Serviço Social. Nesta nova abordagem, «modernity's grand views are replaced by relative truths, more local explanations and multiple perspectives. The postmodern world is more fluid, 
more open to interpretation, more tolerant of diversity, more self-made, and less certain. Postmodernists see no absolute truths» (Howe, 2009: 132).

Contudo, há que manter em mente que pese embora a influência destas perspectivas pós-modernas no Serviço Social, tal não resulta exclusivo desta área de saber mas do reconhecimento de um amplo debate no seio da própria teoria social contemporânea face às diversas transformações sociais.

Hay (2002) vai mais longe nesta organização do pensamento pós-moderno e identifica três dimensões que considera integrarem os principais atributos do pós-modernismo: a dimensão ontológica, epistemológica e metodológica. Deste modo, identifica como característica fulcral das correntes pós-modernas a instauração de uma ontologia da diferença, cujas premissas fundamentais são "o mundo é experimentado de formas diferentes por diferentes observadores; essas experiências possuem especificidade histórica e cultural; essas experiências são únicas e singulares e não são a expressão de processos genéricos» (Hay, 2002: 207).

Por outro lado, revela-nos o cepticismo epistemológico, como segunda característica do pensamento pós-moderno, fundado nas seguintes afirmações: «diferentes posições do sujeito implicam diferentes reivindicações do conhecimento; o conhecimento depende do contexto e da perspectiva adoptada, as reivindicações de verdade não podem ser validadas empiricamente e são dogmáticas e potencialmente totalitárias» (Ibidem).

Por último, Hay fala-nos da adopção de uma metodologia desconstrutivista por parte dos cientistas pós-modernos, que se baseia nas ideias de que " 0 cepticismo epistemológico silencia reivindicações substantivas do conhecimento; as perspectivas modernistas continuam a pressupor um acesso privilegiado à realidade, que é insustentável e potencialmente totalitário em seus efeitos; as técnicas desconstrucionistas podem confrontar essas metanarrativas, chamando à atenção para outras linguagens, que, de outra forma, ficariam marginalizadas" (Ibidem).

Ligadas ao desconstrutivismo proposto por Michel Foucault (1926-1984), Jacques Derrida (1930-2004) e Roland Barthes (1915-1980), as perspetivas pós-modernas vêm promover um corte no corpo do estruturalismo e interrogar criticamente as noções dominantes até então e que perderam o seu sentido na contemporaneidade e nos seus discursos da prática.

Desenvolve-se, neste âmbito, uma prática reflexiva que, mais do que visar a constituição de um conhecimento estabilizado, pretende o desenvolvimento das capacidades de reflexividade e de acção, tendo em vista o engajamento entre «as nossas 'verdades', 'histórias' e 'construções' e as dos outros» (Parton et al., 1998: 248). 
A importância deste tipo de prática constitui, segundo Howe, «(...) the basis of a well-articulated approach to social work, that blends elements of postmodernism, post structuralism, critical social work, reflective practice and reflexivity» (Howe, 2009: 171).

Para Howe, o processo de reflexão crítica é realizado em dois momentos: análise e mudança «the stage of analysis is one of deconstructtion, of critical reflection. The worker and user become aware of other people's use and miss-use of power. The change stage is one of re-construction. It is at this point in the relationship that service users begin to re-value themselves. (...) Reflection, then, is one of the process through which clients participate in social work» (Howe, 2009: 172-173).

Também para Payne a importância da reflexividade constitui uma característica das teorias mais modernas do trabalho social que reconhece a necessidade de estar em constante mudança para responder às construções práticas dos sujeitos, não podendo, portanto gerar reconhecimentos universais (Payne, 2002: 45).

Tal reconhecimento implica, uma alteração do enfoque. Se no pensamento moderno encontramos um enfoque dedutivo, adoptado pelo Serviço Social crítico durante ao século XX, Foulcault, numa perspectiva crítica pós-estrutural insiste numa visão ascendente de análise (indutiva), defendendo uma investigação que tenha início nos contextos específicos da prática social (Foulcault, 1978 e 1991 in Healy, 2001) e que parte do reconhecimento do uso e importância da intuição e arte na prática profissional (Fook, 2001). Tudo isto numa abordagem holista e feita a partir de abordagens experimentais e não-positivistas.

Ao aplicar esta perspectiva reflexiva à prática profissional, ela assume-se por uma intervenção na qual: «Reflective practitioners are those who can situate themselves in the context of the situation and can factor this understanding into the ways in which they practise» (Fook, 2001: 40). Trata-se de um processo on going de reflexão e que permite aos interventores desenvolverem a sua teoria directamente a partir da sua experiência. Para além disso, permite 'adaptar' a sua intervenção a cada contexto específico, recorrendo para tal a um leque de competências e perspectivas não pré-definidas (como nos métodos mais tradicionais).

Neste sentido, e conforme nos propõe Fook (2001), a teoria é redefinida e assume-se como um conjunto de ferramentas intelectuais que prevêem um quadro inicial de referência a partir da qual é possível dar sentido a novas situações. Ao fazer isso, ela liberta a teoria da prática da noção de esta ser um conjunto normativo de regras (que raramente são aplicados na prática), para 
passar a ser um processo que permite aos assistentes sociais pensar no que eles precisam de saber para levar a cabo a sua prática diária.

O contributo deste tipo de ideias para abordagem crítica e pós moderna do Serviço Social é claro: reconhece múltiplas e diversas construções; o conhecimento é construído de forma inclusiva, integrando quer a experiência quer o processo reflexivo sobre esta; a comunicação e o diálogo constituem importantes processos de negociação das próprias estruturas e relações.

\section{Conclusão}

Apesar da vitalidade do marxismo como paradigma de análise e compreensão da realidade e apesar da manutenção da hegemonia do projecto profissional caracterizado pela ruptura com o conservadorismo que caracterizou a trajectória do Serviço Social, permanecem neste início do século XXI questões, em torno dos paradigmas clássicos e a busca de construção de novos paradigmas que se colocam pela apropriação do pensamento de autores contemporâneos de diversas tendências teórico-metodológicas como Anthony Giddens, Hannah Arendt, Pierre Bourdieu, Michel Foucault, Jurgen Habermas, Edgar Morin, Boaventura Souza Santos, Eric Hobsbawm, E.P. Thompson e tantos outros.

Efectivamente, coloca-se como desafio à profissão ao longo neste início de milénio a consolidação do projecto ético político, teórico metodológico e operativo que vem construindo particularmente sob a influência da tradição marxista, «mas incorporando valores auridos noutras fontes e vertentes $e$, pois sem vincos estreitos ou sectários, aquelas matrizes estão directamente conectadas ao ideal de socialidade colocado pelo programa da modernidade - neste sentido, tais matrizes não são 'marxistas' nem dizem respeito apenas aos marxistas, mas remetem a um largo rol de conquistas da civilização e, do ponto de vista profissional, concretizam um avanço que é pertinente a todos os profissionais que, na luta contra o conservadorismo, não abrem mão daquilo que o velho Lukács chamava de 'herança cultural'.» (Netto, 1996: 117).

\section{Bibliografia}

Adams, R., Dominelli, L., \& Payne, M. (2009). Critical Pratice in Social Work. New York: Palgrave Macmillan.

Adams, R., Dominelli, L., \& Payne, M. (Eds.). (2002). Social Work. Themes, Issues and Critical Debates. 2. ${ }^{a}$ ed. New York: Palgrave Macmillan.

AHLERT, A. (s.d.). A teoria da ação comunicativa como paradigma para a formação ética. IEPG/EST. RS: Brasil. 
Coulshed, V. (1991). Social Work Practice: An Introduction. London: Basingstoke Macmillan - now Palgrave Macmillan.

Dominelli, L. (1997). Sociology for Social Work. London: Basingstoke Macmillan - now Palgrave Macmillan.

Fook, J. (2001). Social Work: Critical Theory and Practice. London: Sage.

Freire, P. (1970). Pedagogy of the Opressed. New York: The Continuum Publhing Company.

Guess, R. (1988) Teoria Crítica: Habermas e a Escola de Frankfurt. Campinas: Papirus.

Habermas, J. (1990). O discurso filosófico da modernidade. Lisboa: Dom Quixote.

HABERMAS, J. (1998). Between Facts and Norms: Contributions to a Discourse Theory of Law and Democracy. Trans. W. Rehg. Cambridge, MA: MIT Press.

HABERMAS, J. (1987). Teoría de la acción comunicativa I: racionalidad de la acción y racionalización social. $4^{\mathrm{a}}$ ed. Madrid: Taurus.

HaY, C. (2002). Political Analysis. A critical introduction. New York: Palgrave Macmillan.

HoRkHEIMER, M., \& AdORNO, T. W. (1995). Dialéctica do esclarecimento: fragmentos filosóficos. Rio de Janeiro: Jorge Zahar Ed.

HowE, D. (2009). A brief introduction to social work theory. New York: Palgrave Macmillan.

Howe, D. (2008). The Emotionally Intelligent Social Worker. New York: Palgrave Macmillan.

HeALY, K. (2001). Trabajo Social: perspectivas contemporâneas. Madrid: Ediciones Morata. Fundación Paideia.

NetTo, J. P. (1996). «Transformações Societárias e Serviço Social - notas para uma análise prospectiva da profissão no Brasil». In: Serviço Social e Sociedade n. 50. São Paulo: Cortez. Abril.

PARTON, N. (2004). Constructive social work - towards a new practice. London: Macmillen Press.

Payne, M. (2002). Teoria do Trabalho Social Moderno. Coimbra: Quarteto.

PARSLOE, P. (1996). Pathways to Empowerment, Birmingham: Venture.

Restrepo, O. (2003). Reconfigurando el Trabajo Social. Perspectivas y Tendencias Contemporáneas. Buenos Aires: Espacio Editorial. 